\title{
Dinâmica de sementes de Bidens pilosa no solo(1)
}

\author{
Ricardo Carmona( ${ }^{(2)}$ e Hugo Dias da Costa Villas Bôas(3)
}

Resumo - Sementes de picão-preto (Bidens pilosa L.) foram enterradas no solo nas profundidades de $0 \mathrm{~cm}$ e $10 \mathrm{~cm}$, com ou sem cobertura morta (palhada seca de milheto), com o objetivo de testar o efeito destas variáveis na viabilidade e dormência das sementes, durante o período de um ano. Avaliou-se o número de sementes germinadas e firmes; as sementes firmes remanescentes no solo foram submetidas a germinação em duas condições, para estimar a viabilidade e dormência, respectivamente. A germinação e o decréscimo de sementes no solo foram mais acentuados na superfície do solo. O decréscimo de sementes foi mais intenso na primeira estação chuvosa, reduzindo-se na estação seca até a segunda estação chuvosa. Constataram-se ciclos de dormência nas sementes, com liberação na época chuvosa, e indução na estação seca. Não foi observado efeito da palhada, provavelmente em razão de sua rápida decomposição sem subseqüente reposição. Estes resultados evidenciam que práticas que favoreçam a concentração das sementes desta espécie na superfície do solo, como o plantio direto, podem ocasionar maiores fluxos de germinação a curto prazo, o que requer maiores cuidados no manejo, mas acabam sendo vantajosas a médio e longo prazo, por acelerar o decréscimo no banco de sementes no solo.

Termos para indexação: plantas daninhas, plantio direto, capacidade germinativa, dormência da semente, viabilidade.

\section{The dynamics of Bidens pilosa seeds in the soil}

\begin{abstract}
Bidens pilosa L. seeds were buried at $0 \mathrm{~cm}$ and $10 \mathrm{~cm}$ depths in the soil, with or without millet mulch, to test the effect of these variables on seed viability and dormancy during one year. The numbers of germinated and firm seeds were evaluated; the remained firm seeds in the soil were germinated in two environmental conditions, to estimate seed viability and dormancy, respectively. The germination and decay of seeds were more intense on the soil surface. Seed depletion was higher during the first rainy season and decreased during the dry season until the second rainy season. The mulch had no effect on seed depletion, probably due to its fast decomposition and no subsequent reposition. These results show that the concentration of B. pilosa seeds on the soil surface, by practices such as no-tillage, can increase seedling emergence on short-term, which demands weed control practices, but at long-term it increases the depletion rate of the seed bank in the soil
\end{abstract}

Index terms: weeds, direct sowing, germinability, seed dormancy, viability.

\section{Introdução}

O banco de sementes e propágulos vegetativos no solo constitui a principal fonte de regeneração de plantas daninhas em áreas agrícolas (Carmona, 1992).

\footnotetext{
(1)Aceito para publicação em 10 julho 2000.

(2)Universidade de Brasília (UnB), Faculdade de Agronomia e Medicina Veterinária, Caixa Postal 4508, CEP 70910-970 Brasília, DF. E-mail: rcarmona@unb.br

(3)Embrapa-Serviço de Negócios para Transferência de Tecnologia, Caixa Postal 40315, CEP 70770-901 Brasília, DF E-mail: Hugo.Villas.Boas@embrapa.br
}

O banco de sementes apresenta dinâmica própria, que varia conforme a espécie, condições da semente, ocorrência de predadores e fatores ambientais (Carmona, 1995). A dinâmica populacional das várias espécies vegetais resulta da conjugação de todos estes fatores, aliados aos constantes ingressos de sementes. $\mathrm{O}$ ingresso ocorre principalmente pela produção de sementes das plantas que colonizam a área e, em menor escala, pela entrada de sementes exógenas, através de vários agentes, como: vento, água e animais. As perdas verificam-se pela germinação, deterioração, predação e transporte. O conhecimento da dinâmica dos bancos de sementes nas diversas espé- 
cies é fundamental para a proposição de métodos mais racionais de manejo de plantas daninhas (Murdoch \& Carmona, 1993).

A espécie Bidens pilosa é originária da América Tropical, com maior ocorrência na América do Sul. Encontra-se, atualmente, disseminada em quase todo o território brasileiro e sua maior concentração é verificada nas áreas agrícolas do centro-sul, onde constitui uma das piores plantas daninhas a infestar culturas anuais; é apontada como tal em mais de 40 países (Kissmann \& Groth, 1992). Apesar da baixa capacidade competitiva de plantas individuais, esta espécie desenvolve-se em altas densidades nas áreas cultivadas, o que lhe confere grande capacidade competitiva (Akobundu, 1987). É uma das principais hospedeiras de nematóides do gênero Meloidogyne, que atacam plantas cultivadas. Apresenta, no entanto, algumas características úteis ao homem, quase não exploradas, podendo mesmo ser utilizada como planta forrageira, na fabricação de bebidas (África) e principalmente como planta medicinal.

A grande adaptação desta espécie a ambientes agrícolas deve-se, em parte, à sua grande produção de sementes, aliada a mecanismos de dormência. De acordo com Lorenzi (1991), uma única planta chega a produzir de 3.000 a 6.000 sementes, a maioria das quais germina prontamente após a maturação, garantindo, assim, três a quatro gerações anuais. Mecanismos de dormência possibilitam que sementes enterradas profundamente no solo apresentem ao redor de $80 \%$ de germinação, após três a cinco anos (Lorenzi, 1991).

A distribuição vertical de sementes ao longo do perfil do solo, a qual apresenta estreita correlação com o tipo de preparo, afeta as condições ambientais às quais as sementes estão sujeitas. De acordo com as observações de Klein \& Felippe (1991), a luz estimulou a germinação de sementes de $B$. pilosa, aumentando de $50 \%$ no escuro para $70 \%$ em presença de luz, com temperatura constante. Na superfície do solo, além da maior quantidade de luz, a alternância de temperaturas também pode estimular a germinação de um grande número de espécies. Se estas hipóteses forem verdadeiras, a técnica do plantio direto deve acelerar o decréscimo de sementes de B. pilosa no solo, por concentrá-las próximo à superfície (Ball, 1992; Schreiber, 1992; Yenish et al., 1992).
O objetivo deste trabalho foi avaliar o efeito da profundidade das sementes no perfil do solo e da presença da palha, na germinação, dormência e viabilidade de sementes de B. pilosa, ao longo de um ano.

\section{Material e Métodos}

O presente trabalho foi conduzido na Fazenda Sucupira da Embrapa, no Distrito Federal. O solo no local é classificado como Latossolo Vermelho-Escuro, com a seguinte composição granulométrica: $280 \mathrm{~g} \mathrm{~kg}^{-1}$ de areia, $340 \mathrm{~g} \mathrm{~kg}^{-1}$ de silte e $380 \mathrm{~g} \mathrm{~kg}^{-1}$ de argila. A análise química apresentou como resultados: $\mathrm{pH}$ em água de 5,$8 ; 1,2 \mathrm{cmol}_{\mathrm{c}} \mathrm{dm}^{-3}$ de $\mathrm{Ca} ; 0,8 \mathrm{cmol}_{\mathrm{c}} \mathrm{dm}^{-3}$ de $\mathrm{Mg} ; 0,08 \mathrm{cmol}_{\mathrm{c}} \mathrm{dm}^{-3}$ de $\mathrm{K}$; $0,01 \mathrm{cmol}_{\mathrm{c}} \mathrm{dm}^{-3}$ de $\mathrm{Na} ; 0,2 \mathrm{cmol}_{\mathrm{c}} \mathrm{dm}^{-3}$ de Al; $5,5 \mathrm{cmol}_{\mathrm{c}} \mathrm{dm}^{-3}$ de acidez total $(\mathrm{H}+\mathrm{Al}) ; 9 \%$ de saturação de $\mathrm{Al} ; 28 \%$ de saturação de bases; $29,2 \mathrm{~g} \mathrm{~kg}^{-1}$ de matéria orgânica e $9 \mathrm{mg} \mathrm{dm}^{-3} \mathrm{de} P$.

Os aquênios, ou sementes, de B. pilosa foram coletados em infestações naturais da espécie, em área de pousio de soja, no Município de Buritis, MG, próximo à Serra Bonita, no dia 28 de outubro de 1995. Coletaram-se as sementes manualmente, maduras, na fase de desprendimento, sendo posteriormente homogeneizadas e limpas com o uso de peneiras. $\mathrm{O}$ armazenamento das sementes até a data de enterrio foi feito em sacos de papel, em condições ambientais de laboratório. Antes do enterrio executaramse testes de germinação nas sementes, em diferentes condições, para determinar sua viabilidade e dormência.

As embalagens utilizadas para o enterrio consistiram de sacos de $10 \times 10 \mathrm{~cm}$ de tela sombrite $70 \%$, cada um contendo 300 sementes cheias (germinadas + firmes). A porcentagem de sementes cheias no lote havia sido determinada, antes, mediante teste de germinação, em condições favoráveis, seguido de pressão nas sementes não germinadas. As embalagens foram fechadas com máquina de costura, para evitar a perda das sementes, e fixadas com estacas metálicas ao solo. O experimento foi instalado no campo, no dia 11/1/96, sendo a germinação das sementes avaliada nesta data em duas condições ambientais, conforme método descrito adiante. No centro de cada parcela, foram alocados dois sacos, um em cada profundidade $(0 \mathrm{~cm}$ e $10 \mathrm{~cm})$, perfazendo um total de 48 parcelas de $1,8 \times 1,3 \mathrm{~m}$, dispostas em delineamento do tipo blocos casualizados. A cobertura morta foi feita logo após o enterrio das sementes, com $6 \mathrm{t} \mathrm{ha}^{-1}$ de palhada de milheto (Pennisetum typhoideum) secada a ar, e picada em picador de forragem (fragmentos de 2 a $3 \mathrm{~cm}$ de comprimento). As coletas foram efetuadas nas seguintes datas: 19/3, $21 / 5,25 / 7,18 / 9,29 / 10$ e 16/12 de 1996. 
A umidade (em base úmida) do solo foi monitorada a cada cinco dias, durante o transcorrer do experimento, nas duas profundidades e coberturas. Cada amostragem constou de duas subamostras de aproximadamente $100 \mathrm{~g}$ de solo, coletadas entre $11 \mathrm{~h}$ e $12 \mathrm{~h}$ da manhã. Utilizou-se o método direto da estufa a $105^{\circ} \mathrm{C}$ durante 24 horas (Brasil, 1992). A temperatura do solo também foi monitorada durante o experimento, nas duas profundidades e coberturas, com a utilização de termógrafos

As coletas foram realizadas à noite, a fim de evitar o efeito da luz no nível de dormência das sementes. As embalagens foram envolvidas em duas camadas de papel-alumínio, acondicionadas em caixas de papelão totalmente vedadas e transportadas ao laboratório. Todas as operações realizadas no laboratório foram conduzidas à noite, em ambiente iluminado apenas com luz verde de segurança, através de uma lâmpada fosforescente (10 watts) submersa em solução aquosa de $\mathrm{CuCl}_{2}$, que emite irradiação com comprimento de onda na faixa de 495-550 nm (de absorção praticamente desprezível pelo fitocromo).

As embalagens foram lavadas em água corrente, para eliminar o solo aderido. Em seguida, foram abertas, e o conteúdo, lavado sobre peneiras e tratado com hipoclorito de sódio a $1 \%$, sendo novamente lavado com água destilada. As sementes germinadas foram contadas e descartadas, e as demais remanescentes, divididas, para a realização de testes de germinação em duas condições ambientais Os testes foram montados em caixas gerbox forradas com duas folhas de papel mata-borrão umedecidas com $15 \mathrm{~mL}$ de água ou nitrato de potássio. Para estimar a viabilidade das sementes em cada época, os testes foram feitos sob temperaturas alternadas de $20^{\circ} \mathrm{C}$ e $30^{\circ} \mathrm{C}$, durante 16 e 8 horas, respectivamente, em solução de nitrato de potássio $(0,2 \%)$ em presença de luz. Os testes realizados a $20^{\circ} \mathrm{C}$, em água e na ausência de luz, foram usados para avaliar o estado de dormência das sementes. A ausência de luz foi obtida revestindo-se as caixas gerbox com duas folhas de papel-alumínio. Os testes duraram 28 dias, com avaliações semanais da germinação e, ao final, também das sementes firmes e mortas. As avaliações do teste a $20^{\circ} \mathrm{C}$ foram feitas no escuro com a mesma luz verde de segurança descrita anteriormente

Consideraram-se germinadas as sementes que emitiram pelo menos $3 \mathrm{~mm}$ de radícula. As sementes firmes foram diferenciadas das mortas, quando submetidas a uma leve pressão com pinça: as sementes mortas cediam à pressão com facilidade, e o tegumento se rompia, deixando sair o material deteriorado em forma mais líquida; as firmes eram mais resistentes à pressão e os tecidos embrionários, sendo mais consistentes, eram expostos na forma sólida. Consideraram-se decréscimo no banco de semen- tes as perdas por germinação e mortalidade no campo. Não se verificou predação das sementes, provavelmente pela maior proteção conferida pela embalagem. Consideraramse viáveis as sementes germinadas, somadas às firmes.

\section{Resultados e Discussão}

O decréscimo de sementes de $B$. pilosa foi bastante acentuado logo após o enterrio, no período de janeiro a março, o que coincidiu com a época de chuvas, quando a umidade do solo e as temperaturas apresentavam-se mais elevadas (Figuras 1, 2, 3 e 4). Logo após este período, o número de sementes viáveis no solo permaneceu mais ou menos constante até o final do experimento. Esta tendência foi observada em todas as situações, nas sementes coletadas da superfície e a $10 \mathrm{~cm}$ de profundidade, na presença e na ausência de cobertura morta. Aparentemente, a maior causa de decréscimo foi a deterioração das sementes, que levou à perda de viabilidade no solo.

A profundidade das sementes no perfil do solo afetou bastante o decréscimo de sementes desta espécie (Figura 4). Verificou-se que as sementes na superfície decaíram muito mais rapidamente do que as enterradas a $10 \mathrm{~cm}$ de profundidade. Assim, menos de $20 \%$ das sementes iniciais permaneceram viáveis, sem germinar, na superfície do solo, até o final do experimento. Aproximadamente 50\% das sementes enterradas permaneceram viáveis até dezembro (Figura 4). Decréscimo mais acentuado na superfície do solo em relação às sementes enterradas também foi verificado em outras espécies, como Rumex crispus (Carmona, 1993), R. obtusifolius (Weaver \& Cavers, 1979) e Agropyron repens (Williams, 1978).

As principais causas de decréscimo foram a germinação e a perda de viabilidade, as quais foram muito mais intensas na superfície do que a $10 \mathrm{~cm}$ de profundidade. A germinação no campo sempre foi superior nos sacos situados na superfície do solo em relação aos enterrados a $10 \mathrm{~cm}$ de profundidade (Figura 5). Este fato demonstra que o ambiente é mais propício à regeneração desta espécie na superfície do solo do que em maiores profundidades.

O efeito da cobertura não foi evidente no decréscimo de sementes de B. pilosa (Figura 5). A decomposição da palhada foi relativamente rápida, prova- 
velmente por haver sido colocada em época chuvosa e com altas temperaturas médias, e no restante do tempo o solo foi mantido descoberto. O curto período de recobrimento do solo pode ter-se constituído na mais provável causa de falta de efeito da palhada neste experimento.

As sementes coletadas no campo ao longo do ano, quando testadas em laboratório, tiveram sua germinação bastante afetada pelas condições do teste (Figura 6). A utilização de temperaturas alternadas, com nitrato de potássio e luz, estimularam a germinação das sementes. Quase a totalidade das sementes firmes coletadas no solo ao longo do ano germinou nessas condições, o que comprova que se encontravam viáveis e dormentes no solo. Por outro lado, nos testes conduzidos em temperatura constante, em água e no escuro, observou-se germinação inferior nas

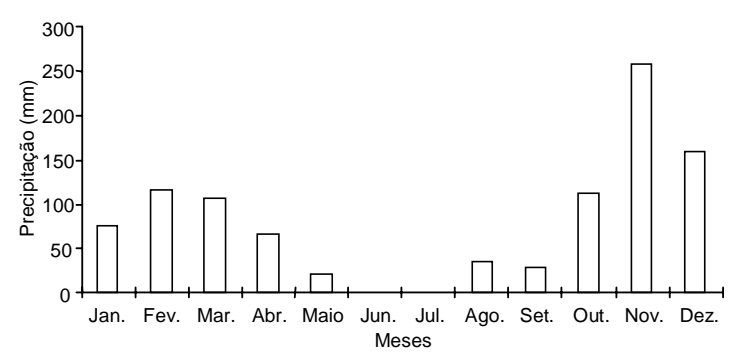

Figura 1. Precipitação pluvial mensal $(\mathrm{mm})$ no ano de 1996 na Fazenda Sucupira (Embrapa), Brasília, DF

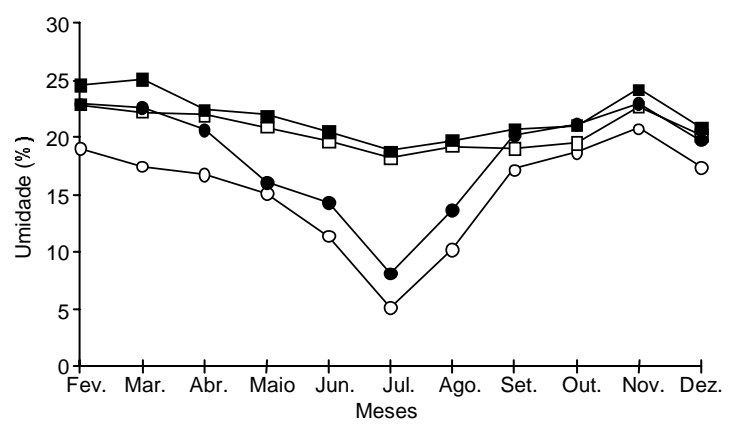

Figura 2. Umidade média mensal (\% em base úmida) do solo, ao longo do ano de 1996 na superfície $(\bigcirc, 0)$ e a $10 \mathrm{~cm}$ de profundidade ( na presença sência $(O, \square)$ de cobertura morta. Fazenda Sucupira (Embrapa), Brasília, DF. várias épocas de coleta. Aparentemente, apenas as sementes que estavam livres de dormência ou com baixo nível de dormência foram capazes de germinar nas condições de temperatura constante. Desta forma, este teste foi utilizado para estimar a dormência das sementes neste estudo.

Utilizando-se os resultados de germinação nas duas condições ambientais de laboratório, foi possível identificar ciclos de dormência nas sementes de B. pilosa enterradas no solo (Figura 6). Na época do enterrio, ao redor de $20 \%$ e $70 \%$ das sementes firmes deixaram de germinar nas condições de temperatura alternada e constante, respectivamente. Isto indica a ocorrência de dormência primária (ou nata) nas sementes recém-desprendidas desta espécie. Algumas sementes aparentemente encontravam-se com uma dormência muito profunda, pois deixaram de germinar mesmo nas condições mais favoráveis de teste. Verificou-se uma redução acentuada no nível de dormência primária já na primeira coleta, ocorrida no mês de março. A partir desta época, praticamente não foi possível verificar a ocorrência de
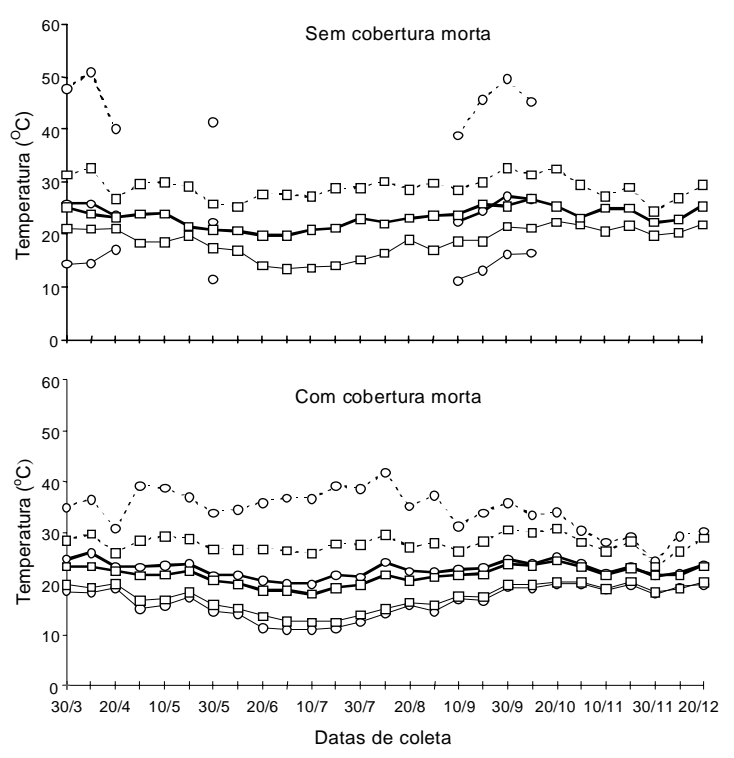

Figura 3. Temperaturas máximas (linhas tracejadas), médias (linhas grossas) e mínimas (linhas finas) do solo $\left({ }^{\circ} \mathrm{C}\right)$, na superfície (o) e a $10 \mathrm{~cm}$ de profundidade $(\square)$, na ausência e presença de cobertura morta. Médias por decêndio, ao longo do ano de 1996. Fazenda Sucupira (Embrapa), Brasília, DF. 
dormência nas sementes nos testes nas condições promotoras, exceto na coleta de setembro, quando uma pequena proporção das sementes viáveis coletadas a $0 \mathrm{~cm}$ e $10 \mathrm{~cm}$ não germinaram. Por outro lado, nas condições menos promotoras, foi possível identificar um ciclo anual de dormência secundária (ou induzida) nas sementes. Este ciclo foi mais evidente nas sementes enterradas a $10 \mathrm{~cm}$ de profundidade, provavelmente em virtude da maior quantidade de sementes restantes. Nesta profundidade, as sementes germinaram melhor na coleta de março nas condições de temperatura constante, quando a dormência primária havia sido superada. No período de março a setembro, houve um aumento no nível de dormência nas sementes (secundária ou induzida), que coincide com a fase seca do ano. Após setembro, o nível de dormência sofreu um decréscimo, quando iniciou o período chuvoso.

A região dos cerrados brasileiros é caracterizada por duas estações bem definidas ao longo do ano, uma seca e outra chuvosa (Spehar, 1996). Observase uma clara concentração das chuvas no período de outubro a abril (Figura 1), o que reflete na umidade do solo (Figura 2). Ocorre também uma variação na temperatura ao longo do ano, com queda durante o

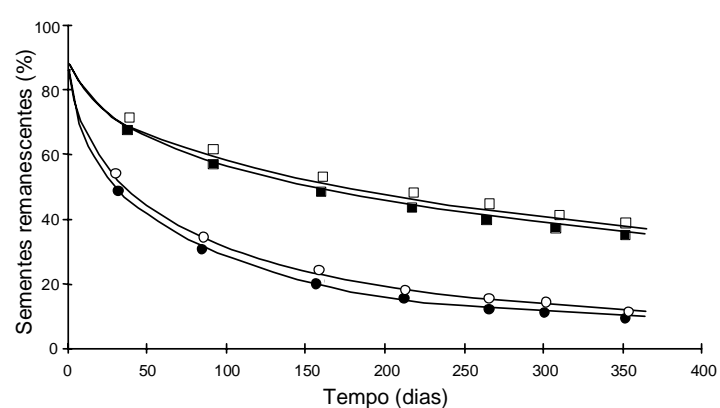

Figura 4. Sementes viáveis remanescentes (SVR) de B. pilosa no solo em razão do tempo (T), nas profundidades de $0 \mathrm{~cm}$ e $10 \mathrm{~cm}$, na ausência e presença de cobertura morta logo após o enterrio. As curvas foram definidas pelas seguintes equações: a) $0 \mathrm{~cm}$, sem cob.: $\mathbf{O S V R}=97,15$ $\left.1,35 \mathrm{~T}+6,8 \cdot 10^{-3} \mathrm{~T}^{2}-10,66 \cdot 10^{-6} \mathrm{~T}^{3}\left(\mathrm{r}^{2}=0,96\right) ; \mathrm{b}\right) 0 \mathrm{~cm}, \mathrm{com}$ cob.: $\bigcirc \mathrm{SVR}=98,19-1,20 \mathrm{~T}+5,8 \cdot 10^{-3} \mathrm{~T}^{2}-8,93 \cdot 10^{-6} \mathrm{~T}^{3}$ $\left(\mathrm{r}^{2}=0,97\right)$; c) $10 \mathrm{~cm}$, sem cob.: $\mathrm{SVR}=98,63-0,95 \mathrm{~T}+$ $4,8 \cdot 10^{-3} \mathrm{~T}^{2}-7,40 \cdot 10^{-6} \mathrm{~T}^{3}\left(\mathrm{r}^{2}=0,89\right)$; d) $10 \mathrm{~cm}$, com cob. $\square \mathrm{SVR}=99,31-0,98 \mathrm{~T}+5,0 \cdot 10^{-3} \mathrm{~T}^{2}-7,74 \cdot 10^{-6} \mathrm{~T}^{3}$ $\left(r^{2}=0,88\right)$ período seco (Figura 3), porém esta variação não é tão intensa quanto em regiões de mais alta latitude. Aparentemente, a variação nas condições ambientais do solo afeta a dormência de sementes de B. pilosa. A perda de dormência primária ocorreu rapidamen-
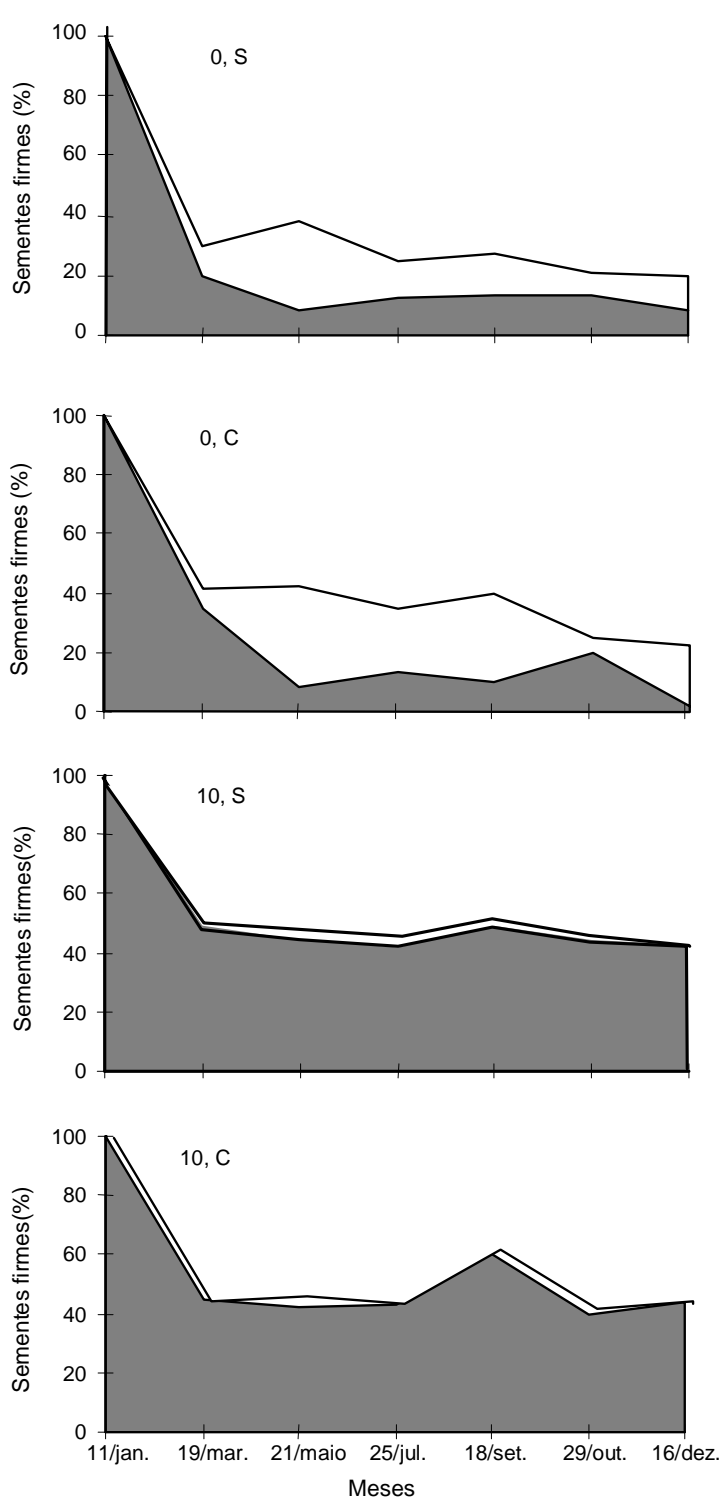

Figura 5. Porcentagem de sementes firmes (área hachurada) e germinadas (área branca) no campo, em B. pilosa. As sementes foram coletadas na superfície (0) ou a $10 \mathrm{~cm}$ de profundidade (10), em presença (C) ou ausência (S) de cobertura morta. 

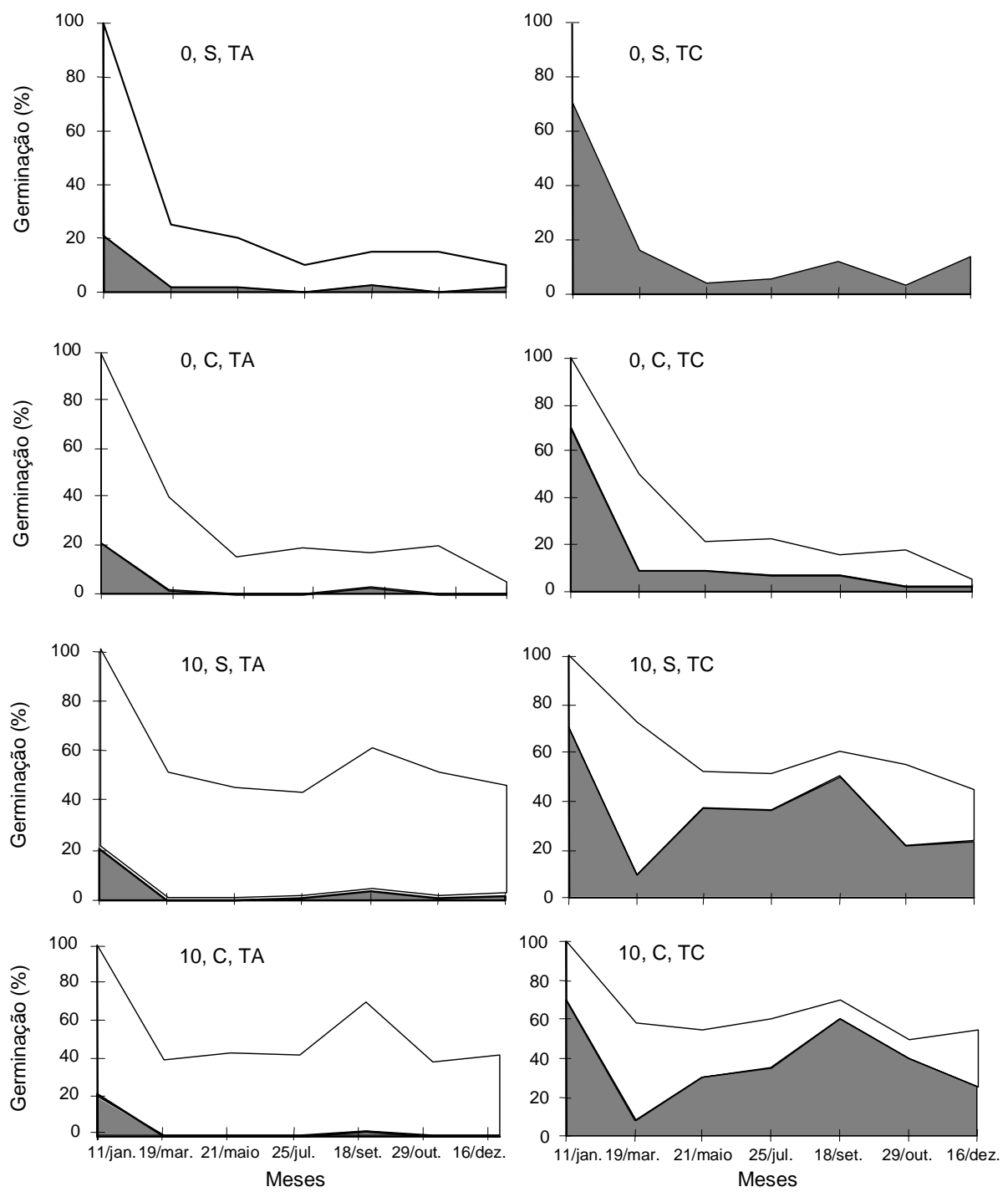

Figura 6. Porcentagem de germinação (área branca) e de sementes firmes (área hachurada) em B. pilosa. As sementes foram coletadas ao longo do ano na superfície $(0)$ e a $10 \mathrm{~cm}$ de profundidade (10), em presença (C) ou ausência (S) de cobertura morta. Os testes foram conduzidos em laboratório às temperaturas de $20 / 30^{\circ} \mathrm{C}$ com luz e nitrato de potássio (TA) e a $20^{\circ} \mathrm{C}$ em água e no escuro (TC)

te no período chuvoso, coincidindo com as maiores temperaturas e umidade do solo. Como resultado, algumas sementes germinaram no campo, nesta época. As sementes que não germinaram na época chuvosa apresentaram uma indução de dormência secundária, que coincidiu com o período seco do ano. Esta indução pode contribuir para a falta de germinação durante o período seco, quando eventuais elevações na umidade do solo são possíveis, em razão da ocorrência de chuvas anômalas. Com o início de nova estação chuvosa, no período de setembro a dezembro, a dormência secundária aparentemente decaiu.

A confirmação da ocorrência de ciclos de dormência nas sementes apresenta um significado mui- 
to grande na proposição de métodos mais racionais e eficientes de manejo de plantas daninhas (Murdoch \& Carmona, 1993). Práticas que estimulem a germinação de sementes no campo, como a aplicação de compostos superadores de dormência, apresentam chances muito maiores de sucesso se as sementes estiverem com baixo nível de dormência, aliado a condições ambientais favoráveis em termos de umidade, temperatura e $\mathrm{pH}$ do solo (Carmona \& Murdoch, 1995; Carmona, 1997).

O preparo do solo tem grande influência no decréscimo de sementes de $B$. pilosa. No sistema plantio direto, onde as sementes permanecem na superfície do solo ou próximo a ela, o decréscimo desta espécie deve ser mais rápido ao longo do tempo.

\section{Conclusões}

1. A germinação e o decréscimo de sementes de Bidens pilosa são mais rápidos na superfície do solo em relação às sementes enterradas a $10 \mathrm{~cm}$ de profundidade em região de cerrados.

2. A dormência secundária das sementes desta espécie é induzida no período seco, reduzindo-se durante o período chuvoso.

3. A viabilidade de sementes desta espécie pode ser avaliada de forma satisfatória utilizando-se temperaturas alternadas de $20^{\circ} \mathrm{C}$ e $30^{\circ} \mathrm{C}$, com luz e nitrato de potássio $(0,2 \%)$ e a dormência à temperatura de $20^{\circ} \mathrm{C}$, no escuro em água.

\section{Referências}

AKOBUNDU, I. O. Weed science in the tropics principles and practices. Norwich : J. Wiley, 1987. $522 \mathrm{p}$.

BALL, D. A. Weed seed bank response to tillage, herbicides, and crop rotation sequence. Weed Science, Champaign, v. 40, n. 4, p. 654-659, 1992.

BRASIL. Ministério da Agricultura e Reforma Agrária Regras para análise de sementes. Brasília : Secretaria Nacional de Defesa Agropecuária, 1992. 365 p.

CARMONA, R. Bancos de sementes e o estabelecimento de plantas daninhas em alguns agroecossistemas. Planta Daninha, Brasília, v. 14, n. 1, p. 3-8,1995

CARMONA, R. Influência das variações estacionais e profundidade de sementes no solo na dormência e germinação em Rumex crispus L. Planta Daninha, Brasília, v. 11, n. $1 / 2$, p. $29-36,1993$.
CARMONA, R. Influência do pH na resposta de sementes de plantas daninhas a substâncias promotoras de germinação. Planta Daninha, Botucatu, v. 15, n. 1, p. 3-17, 1997.

CARMONA, R. Problemática e manejo de bancos de sementes de invasoras em solos agrícolas. Planta Daninha, Brasília, v. 10, n. 1/2, p. 5-16, 1992.

CARMONA, R.; MURDOCH, A. J. Interactions of temperature and dormancy-relieving compounds on the germination of weed seeds. Seed Science Research, Wallingford, v. 5, p. 227-236, 1995.

KISSMANN, K. G.; GROTH, D. Plantas infestantes e nocivas. São Paulo : BASF Brasileira, 1992. t. 2.

KLEIN, A.; FELIPPE, G. M. Efeito da luz na germinação de sementes de ervas invasoras. Pesquisa Agropecuária Brasileira, Brasília, v. 26, n. 7, p. 955-966, jul. 1991

LORENZI, H. Plantas daninhas do Brasil: terrestres, aquáticas, parasitas, tóxicas e medicinais. 2. ed. Nova Odessa : Plantarum, 1991. $440 \mathrm{p}$

MURDOCH, A. J.; CARMONA, R. The implications of the annual dormancy cycle of buried weed seeds for novel methods of weed control. In: BRIGHTON CROP PROTECTION CONFERENCE - WEEDS, 1993, Brighton. Proceedings... Brighton : British Crop Protection Association, 1993. p. 329-334.

SCHREIBER, M. Influence of tillage, crop rotation and weed management on giant foxtail (Setaria faberi) population dynamics and corn yield. Weed Science, Champaign, v. 40, n. 4, p. 645-653, 1992.

SPEHAR, C. Prospects for sustainable grain production systems in the cerrados (Brazilian savannas). In: INTERNATIONAL SYMPOSIUM ON TROPICAL SAVANNAS, 1., 1996, Brasília. Proceedings... Brasília : Embrapa-CPAC, 1996. p. 139-151.

WEAVER, S. E.; CAVERS, P. B. Dynamics of seed population of Rumex crispus and Rumex obtusifolius (Polygonaceae) in disturbed and undisturbed soil. Journal of Applied Ecology, Oxford, v. 16, p. 909-917, 1979.

WILLIAMS, E. D. Germination and longevity of seeds of Agropyron repens L. Beauv. and Agrostis gigantea Roth. in soil in relation to different cultivation regimes. Weed Research, Oxford, v. 18, p. 129-138, 1978.

YENISH, J. P.; DOLL, J. D.; BUHLER, D. D. Effects of tillage on vertical distribution and viability of weed seeds in the soil. Weed Science, Champaign, v. 40, n. 3, p. 429-433, 1992

Pesq. agropec. bras., Brasília, v. 36, n. 3, p. 457-463, mar. 2001 